\title{
LOGOS EN IDEOLOGIA: WOORD EN SKYNWOORD
}

In die jare toe die vrye wểreld 'n doodstryd gevoer het teen die ideologie van ras, bloed en bodem, het $U$, hooggeagte Gemser, die eerste in ons land die ideologie met die Woord gekonfronteer ${ }^{1}$ ). Noudat $U$, na 'n lang en geseënde toewyding aan die diens van die Woord in SuidAfrika, eindelik in die ou moederland, Nederland, aan u ou alma mater, Groningen, $\mathbf{u}$ akademiese weg afgesluit het maar die Woord nog trou beoefen en bedien, skyn dit reg te wees dat teenoor die ideologieë waarvan $\mathrm{U}$ die aantog gesien het en ons die volwassenheid beleef, $u$ leerlinge opnuut die vormwoord, modewoord, skynwoord van die maghebbers toets aan die Woord, die ideologia aan die Logos.

Hoe gerafineerd die ideologie te werke gaan, blyk duidelik daaruit dat dit toe en tans die Woord kom daag en teenspreek in die domein van die Woord self, in die Christelike Kerk. U het toe gewys op die vervolging en smaad wat oor die profeet kom wat waag om die ,so sê die Here" te plaas teenoor die troetel-ideologie van 'n oorwoekerde nasionalisme. So lank die Kerk strydende Kerk bly, sal die lot van die dissipel seker nie anders wees as dié van die Meester wat gesterf het onder die hande van 'n nasionalisme wat uitgeswel het tot 'n ideologie nie.

1) Prof. Dr. B. Gemser, Nasionalisme en Universalisme in die Prediking van die Ou Testament. art. in Almanak van die Ned. Herv. Kerk van Afrika, 1940, bls. 58vv. 
Natuurlik staan Logos en ideologia etimologies nie in teenstelling met mekaar nie. Hulle is inteendeel verwante. Hulle hoef ook nie noodwendig in teenstelling met mekaar te staan nie en tog het "Woord" in sy fundamentele sin en "Ideologie" in sy manifestasie in hierdie twintigste eeu in baie plekke en onder baie omstandighede teenstanders geword wat mekaar verdring. Hul stamverwantskap het plek gemaak vir 'n verskil in betekenis so subtiel enersyds maar so radikaal andersyds as die verskil tussen waarheid en waarskynlikheid. Van Logos verklaar Jesus in sy Hoëpriesterlike Gebed (Joh. 17:17): U Woord is waarheid. Van die godsdiens gebou op en in antwoord op die Woord verklaar een van die ideologieë van ons eeu: „Dis opium vir die volk". Die ideologie van ras, bloed en bodem verklaar by monde van sy eksponent, Alfred Rosen b ERG, die vleesgeworde Woord tot ras-egte blonde Germaan en die Woord wat Hom verkondig tot mythus. Die stryd van die twintigste eeu word by toeneming die stryd tussen Woord en skynwoord, Logos en ideologia. Daarin volg dit sonder afwyking die patroon van die Woord en die weerwoord in die Paradys: „God het gesê ..." en, ,Is dit ook so dat God gesê het ... ?"' Die skynwoord verwerp die Woord nooit heeltemal en direk nie, dit betwyfel dit net en gee daaraan 'n ander uitleg; dit dring Gods Woord in die vorms en die begeertes van mensewoord.

Juis in sy opsetlike gelykenis op die Logos lê die krag van die ideologia. Maar dit is 'n vernietigende $\mathrm{krag}$, soos dié van die Logos 'n reddende $\mathrm{krag}$ is. Mens sou dink dat na soveel eeue van ervaring die wêreld die subtiele onderskeid tussen beide gemaklik sou onderken en dat die skynwoord in ons eeu nie meer 'n bedreiging sou vorm nie. Tog vind die skynwoord, die ideologie, altyd weer aanhangers onder die massa's omdat die mensdom en veral die massa eenvoudig nie sonder 'n gesagvolle woord, 'n betroubare rigsnoer, kan lewe nie. Hulle vra na 'n rigtende uitspraak oor die doel van die lewe en die eindbestemming van die mens. Sonder so 'n geloofwaardige en gesagvolle rigsnoer word die mensdom soos 'n verstoorde miernes. As die Woord ontbreek, aanvaar die wêreld of 'n deel van die wêreld sonder uitsondering 'n ,ersatz"-woord, skynwoord oftewel ideologie.

Dis nie toeval nie dat hierdie eeu van ontkerstening so 'n ryk oes aan ideologieë opgelewer het nie. Die Kerk, die draer van die Woord, het jammerlik uit tred geraak met die tegniese en sosiale ontwikkelinge van hierdie eeu. Dit het die betroubare en gesagvolle Woord nie altyd en oral in die ingewikkelde menslike verhoudinge nagespreek nie; dan is die teruggehoue Woord sonder uitsondering verdring deur die rumoerige skynwoord, die Logos deur die ideologia. Sekerlik, daar is geen eeu waarin die Woord so druk versprei is as in ons tyd nie en tog het die Bybel nie 'n groter invloed nie. Miljoene besit dit as 'n amulet of 'n antieke kunswerk in goeie vertaling.

Daarom is dit wel noodsaaklik om duidelikheid te kry oor die onderskeid tussen Woord en skynwoord, tussen waarheid en waarskyn- 
likheid. Die mens in die geestelike en fisiese chaos van ons tyd moet leer om Logos en ideologia te onderskei.

Wat is dan die Woord, die Logos? Procksch, in Kittel's Theologisches Wörterbuch zum Neuen Testament deel 'n paar fundamentele dinge mee oor die betekenis van die Woord. Hy verklaar in die eerste plek dat die Septuagint se gebruik van die begrip logos bepaal is deur die hebreeuse woordjie dabar; maar ook die stoisynse filosofie wat so veelvuldig gebruik maak van die begrip logos, is daarin afhanklik van dabar, aangesien Zeno self 'n Semiet was. ${ }^{2}$ ) Van twee kante is ons betekenis van woord met die semitiese oersin gelaai, van die bybelse kant en die filosofiese kant. En dabar, in die Septuagint logos, se sin kom eers tenvolle uit in die uitdrukking, débir as naam vir die Heilige der Heilige in die Tempel. Want die woord beteken is sy oorsprong, ,agtergrond", t.w. die agtergrond van die Tempel waar die Heilige der Heilige was. Maar dabar het 'n tweevoudige inhoud: dit omvat die agtergrond, die innerlike realiteit van 'n woord en ook die manifestasie van daardie realiteit in die gebeurtenis. Wie die dabar van 'n gebeurtenis verstaan, verstaan dus ook sy werklike sin.

Hierdie dinamiese karakter van Logos word besonderlik duidelik ten aansien van die Woord van God waarvan mens elke keer weer lees, kai ho logos tou kuriou egeneto, letterlik, ,die Woord van die Here het gebeur ..." Waar woord en gebeurtenis saamval, daar is emet, waarheid. Die verband tussen die Woord en die hoorder van die Woord word uitgedruk deur emoena, d.i. pistis, geloof. Die hoorder bevestig die waarheid van die woord met 'n amen. Die wortel- en betekenisverwante emet, emoena en amen kom nêrens so vol geformuleerd voor as in Openb. 3:14 wat van Christus sê, $\mathrm{Hy}$ is ho amen, ho martus ho pistos kai alethinos, die Amen, die ware en getroue getuie.

Nog een gebruik van dabar: In die débir, die Heilige der Heilige, is die débarim, die Tien Gebooie bewaar, uitdrukking van die innerlike sin van die geskiedenis van Israel en uitdrukking van die heilige wil van God. Maar meer, in die dèbir, die Heilige der Heilige, het die Sékinah, die "tent" van God, d.i. sy teenwoordigheid en heerlikheid, gebly. ${ }^{3}$ )

Woord, waarheid en teenwoordigheid van God word eindelik sigbare manifestasie in die gebeurtenis van die geboorte van Christus soos Joh. 1:14 leer: kai ho logos sarx egeneto kai eskenosen en hemin, en die Woord het vlees geword en het onder ons getent. En dit vervolg om te sê dat daardie woord was pleres charitos kai aletheias, vol van genade en waarheid. In die Johannes-proloog neem die ou profetiese uitdrukking, kai ho logos egeneto die volle tweevoudige sin van dabar aan: die innerlike sin en die uiterlike manifestasie. En Jesus het ook die betrokkenheid daarvan op die $d$ èbir verstaan wanneer Hy sê, ,Breek hierdie Tempel af en in drie dae sal Ek dit oprig". (Joh. 2:19.) En in die Hoë-

2) Theol. Wörterb. IV. 91.

3) T. F. Torrance, Royal Priesthood. London, 1955. p. 1 seq. 
priesterlike Gebed lê Hy die al-oue betrekking tussen Woord en waarheid, "U woord is die waarheid".

Op die amen van die menslike bevestiging of nie bevestiging van die waarheid in die Woord doel Hy wanneer Hy sê, ,Wie my Woord glo, sal lewe..." (Joh. 5:21 wv.) maar-en dis kenmerkend dwarsdeur die geskiedenis-waar die Woord onder mense nie plek het nie, soek selfs kinders van Abraham om Jesus dood te maak. Joh. 8:37. Dit is huiweringswekkend wanneer die Woord swyg, wanneer mens lees, „Jesus het stilgebly" (Mt. 26:63). Waarheid en genade, die heerlikheid van God en sy teenwoordigheid onder die mense verdwyn dan met al wat daar vir $\sin$ en versekering en manifestasie in die dabar, die ordeskeppende Logos, is.

Ideologia is so gesproke ' $n$ betreklik jonge formulering. Dis 'n samestelling uit logos en idea wat visionêre vorm, of vormgewing in idee beteken. Die Oxford woordeboek omskryf dit as ,visionary speculation". Anders as die logos verteenwoordig dit nie die innerlike sin en ook nie die manifestasie van 'n gebeurtenis in die geskiedenis nie. Vir Plato, die vader van die logika en filosoof van die idea is laasgenoemde 'n beginsel van klassifikasie. ${ }^{\text {}}$ )

Nie in sy oorsprong en nie in sy huidige vorm het ideologie iets te doen met waarheid en genade nie; dit projekteer waarskynlikheid en, soos ons sal probeer aantoon, by sy lanseerkussing veroorsaak ideologie konsekwent ongenade. Logos, in sy innerlike sin en oorsprong en gesag, kom van God en manifesteer hom in die geskiedenis onder die mense. Ideologia ontspring aan mense in die geskiedenis, het sy gesag van mense en manifesteer hom nie in waarheid nie maar in praktyke van dwang. Wat die uitkoms van die twee kategorieë betref, logos verwerklik hom in die gebeurtenis en dit heet waarheid; ideologia verwerklik hom nooit in die gebeurtenis nie. Dit bly altyd swewend en spekulatief. As dit sig sou verwerklik, sou dit sigself vernietig want dan sou die waarskynlikheid daarvan openbaar word as onwaarheid.

Die Woord van God ken die formulering ideologia nie. Die begrip is egter wél in die Woord anwesig, telkens waar daar gepraat word van eidola, afgode en eidololatria, afgodediens. Idea en eidolon is stamverwante en beide is deverbatiewe van idein. Laasgenoemde beteken om te sien. Dit wil egter nie sê dat idea en eidolon met die sigbare werklikheid te doen het nie; inteendeel, idea verteenwoordig die visionêre, die nooit sigbaar verwerklikbare nie en eidolon die sigbare vormgewing aan die onwaarheid. Die spekulatiewe ideologia staan nie ver van die eidololatria af nie. Van laasgenoemde sê T. F. TORRANCE, „The appeal of the worship of the nature gods and the feminine deities or Astarot represents the temptation to fashion worship according to forms governed by man's desire ..."5). Ook die ideologie verteenwoordig in laaste instansie die begeerte van die mens. TORRANCE noem die losbreek van die gods-

4) Plato, Euthphr. 6d; Phdr. 265d.

5) Torrance, op.cit., p.5. 
dienstige vorms weg van die Woord van God, 'n poging om druk uit te oefen op God, ,a manipulation of God's will." "). As dit nog nie eidololatria is nie, dan is dit in elk geval al ideologia. Want dit is nou een van die onmiskenbare kwaliteite van ideologie dat dit sig graag en altyd bedien van godsdienstige vorme. Das Deutsche Christentum, eksponent van die Nazi-ideologie, wil die vorm van die godsdiens handhaaf as omkleding van sy onware en onverwerklikbare rasseleer; die Kommunisme, met sy ideologie van 'n paradys vir die proletariër, onderneem om die sosiale geregtigheid te verwerklik wat die Christendom nog nie verwerklik het nie. En kleinere ideologie beloof dié vrede in die land wat die Vredevors gepredik het.

Dit is daarom ook die gevaarlike van die ideologie dat dit poseer met die gesag van die logos. Dis teen die ideologie in die godsdiens dat die Apostel waarsku wanneer hy Timotheüs beveel om die Logos tydig en ontydig te verkondig, ,want daar sal 'n tyd wees wanneer hulle die gesonde leer nie sal verdra nie, maar omdat hulle in hul gehoor gestreel wil wees, vir hulle ' $n$ menigte leraars sal versamel volgens hulle eie begeerlikhede, en die oor sal afkeer van die waarheid en hulle sal wend na die mites".

Omdat die waarheid van die logos blyk uit die saamval van die innerlike betekenis daarvan met die manifestasie in die gebeurtenis, meen die ideologie sy waarheid te moet bewys uit die opeenvolging van die gebeurtenisse in die geskiedenis. Die ideologie ontdek daarom graag in die herhaling in die geskiedenis 'n patroon van idees, noem dit tradisie en gee daaraan die vorm en die kenmerke en die gesag van die Logos. Die ideologie neem à priori aan dat omdat die ideë-patroon 'n min-of-meer samehangende ontwikkeling in sy manifestasie toon, daarom bevat dit, nes die Woord, die innerlike sin van 'n ding, en daarom verteenwoordig die tradisie 'n finale gesag en openbaring van waarheid, netsoos die logos dit doen. Sonder om die tradisies van die vadere uitgesproke met goddelike gesag te beklee, redeneer die ideoloog graag dat die vaders tog nie verkeerd kon wees in hul verstaan van die Woord nie en origens gee hy in die praktyk, so nie in beginsel nie, aan die tradisie in elk geval dieselfde geldigheid as aan die Woord. Albei is waarheid en albei openbaar die innerlike sin van die dinge.

Dat dit so is, weet ook die Woord. Jesus, die vleesgeworde Woord, onderskei tussen Logos en ideologia wanneer Hy tot sewemaal toe sy gesagvolle „Ek sê vir julle” stel teenoor, ,,julle het gehoor dat daar vir die mense van die ou tyd gesê is ..."7) Dis nie sonder betekenis nie dat Jesus hierdie teenstelling maak in 'n perikoop waarin $\mathrm{Hy}$ praat oor die onaantasbaarheid en onverganklikheid van die Woord. Hy veroordeel daarin die skynwoord wat sig aandien onder die dekmantel van die Woord. Logos teenoor Ideologia.

6) id. ibid.

7) vgl. behalwe Ma'th. 5:21-48 ook 15:2vv. 
As draer van die innerlike sin van dinge en manifesteerder van die waarheid is die Logos dikwels bestrawwend, maar dis nooit aggressief nie want dit bly steeds pleres charitos, vol van genade. Die ideologie, al wend hy vrede voor, is nooit anders as aggressief nie, of dit nou die ideologie van die Kommunisme of die rasse-ideologie van die Naziisme of enige ander rasse-ideologie in Europa, Asië of Afrika is. Dis merkwaardig dat die ideologie in sy aggressiwiteit konsekwent eindig met 'n direkte aanval op of ten beste 'n ontkragtiging van die vleesgeworde Logos. Die skynwoord van die Dosetisme het Jesus se bestaan en sterwe tot skyn verklaar sodat die Johanneïese Geskrifte nadruklik moet verklaar : ,W Wat ons gehoor het, wat ons met ons oë gesien het, wat ons aanskou het en ons hande getas het aangaande die Woord..." (I Joh. 1:1, vgl. II Joh. 7). Die rasse-ideologie van die Naziisme verklaar die Woord in die evangeliese berigte aangaande Hom onjuis en verander die Semiet van Nasareth in 'n nasaat van Germaanse swerwers in Galilea. Die Kommunisme verklaar Hom summier tot mite en ander rasse-ideologie wat afstuit op sy gebedsgebod dat sy volk één sal wees, verplaas sy eis tot die gebied van die onsigbare Kerk. Natuurlik skraap elke ideologie vir sy leer 'n patroon uit die geskiedenis bymekaar en beroep hom op egte of gewaande tradisie. Van hierdie vermenging van Woord en skynwoord sê Torrance: „Here there is no room for the prophet, the direct intervention of the charismatic Word, for the Word of God is made of none effect by the traditions of men." ${ }^{8}$ )

Die skynwoord, met sy beroep op tradisie en historiese patroon, roep altyd 'n dooie verlede tot getuienis om die skyn van waarheid en verwerklikbaarheid aan sy swewende en visionêre programme in die hede te gee. Van die Woord verklaar Hebr. 4:12f., zon ho logos tou Theou ... pros hon hemin ho logos, lewend is die Woord ... met wie ons te doen het (letterlik:... met wie ons woord is)". Hierdie uitspraak het origens met die wesentlike kenmerk van die Woord as beskikker oor die innerlike sin van dinge te doen. Dit verklaar dat die lewendige Woord van God indring tot in die diepste wese van 'n mens, en sy innerlikste oorlegginge blootlê. Nou, dit doen die skynwoord nie. Dit verhul en verwar doelbewus die innerlikste motiewe van 'n mens. Die Woord is vox Dei, die skynwoord met sy beroep op die tradisie en die praktyk, is vox populi. Die indringende Woord spreek tot die hart van Jerusalem, die ideologie spreek Jerusalem na die mond.

Dis nodig om uit die talle uitsprake van die Woord oor die Woord nog net een van nader te besien: I Petr. 1:23 sê aan die Woordgelowiges, „,want julle is wedergebore nie uit verganklike saad nie, maar uit onverganklike, deur die lewende Woord van God wat tot in ewigheid bly". Die Woord is dus ewig, dis lewend en dit maak ewig lewend, dis Woord van God. Hiermee staan die skrywer van die brief by die radikale betekenis van dabar. Die skynwoord is presies al hierdie dinge nie. Dis

8) Torrance, op.cit. p.7. 
nie lewend nie want dis as tradisie dooie woord; dis nie lewend nie want dis reeds 'n verlede wat slegs met die kunsmatige asemhaling van die propaganda aan die gang gehou word.

Dit maak nie lewend nie want om die ras en/of die ideologie suiwer te hou, likwideer en maak dit dood. Dit is nie ewig nie maar met die trefkrag van die slagspreuk, die slogan en die mode, skitter dit kortstondig en verdwyn dan soos 'n verouderde filmster. Tweeduisend jaar en meer het die ewigheid en die lewendigheid van die Woord in historie bewys. Die dertiger en veertiger jare van ons eeu het die tydelikheid van die skynwoord bewys. En die ideologieë waarin ons nou nog leef, wat vandag nog gloeiend aanspraak maak daarop dat hulle oor die finale bestemming van mense kan beskik en die wêreld en lande kan hervorm, en met hul vyf- en vyftigjarige programme vir hul besondere nasie, ras en klas die duisendjarige vrederyk op aarde kan bring, word môre dowwe gister. Die skynwoord, nieteenstaande sy aanspraak op gesag op Skriftuurlike grondslae, is nie Gods Woord nie, dit is maar mensewoord. Daarin val woord en gebeurtenis nie saam om emet te openbaar nie; al word dit ook beaam en selfs be-amen deur die vox populi, dit bevat nie emoena, pistis, geloof nie. Dit ontspring juis aan die vertwyfeling en die ongeloof.

Wanneer I Petr. verklaar dat die Woord lewendig is en lewend maak, be-aam hy Joh. 1:1-14 oor die skeppende werksaamheid van die Logos. Skepping hou meteen in kommunikasie en gemeenskap tussen God en mens en ook tussen mens en mens, soos J. A. vaN $W_{Y K}$ aantoon ${ }^{9}$ ). Die ideologie daarenteen verbreek doelbewus kommunikasie en bring programmaties skeiding in die gemeenskap aan op grond van ras, kleur en klas. ${ }^{10}$ ) Inderdaad, terwyl die Logos versamel en verenig, beteken die ideë-leer van Plato ,a principle of classification." ${ }^{11}$ )

Die Logos waarin en waarmee God sy dabar, sy essensiële wese in die gebeurtenis van die historie manifesteer het, is liefde, en het onbeperkte, ongekwalifiseerde liefde gepredik, geleef en volmaakte liefde gesterf en opgestaan. Soortgetrou is die ideologie nooit in sy eie voorstelling die volslae teenoorgestelde van liefde nie. Dis in eie aanspraak selfs 'n soort liefde, 'n liefde met beperkings en kwalifikasies, die eie-liefde oftewel liefde-vir-die-eie en 'n neutrale welwillendheid teenoor die nie-eie solank as laasgenoemde nie sy gesigsveld betree en die uitvoering van sy ideële programme beswaar nie. In werklikheid het die liefde-vir-die-eie van die ideologie met liefde niks te maak nie; dis die tweelingbroer van die haat. Die liefde van die Logos is, leef en vra selfverloëning; die liefde-vir-die-eie be-oog, leef en vra selfbehoud. Van die selfbehoud sê die vleesgeworde Woord, „Elkeen wat sy lewe wil red, sal dit verloor”. Van die selfverloëning sê $\mathrm{Hy}$, ,,Elkeen wat sy lewe om my ontwil verloor, sal dit vind”.

9) Kommunikasie en Menslike Waarde, art. on Vertraagde Aksie, Pretoria, 1960, bls. 105vv. 10) Vertraagde Aksie, bls. 107.

11) LIDDELL and ScOTt, Greek-English Lexicon, s.v. 
Die liefde-vir-die-eie neem in die geskiedenis altyd gestalte aan as nasionalisme. Die gemeenskap van die Woordgelowiges heet Christelik. Die ideologie, om goddelike gesag aan sy credo te gee, verbind graag Christelik met 'n koppelteken aan sy nasionalisme.

In die Israel van God, geroep deur en gebou op die Logos van God, het nasionalisme wel nie opgehou om te wees nie, maar dit het sy bepalende krag en sy uitsluitende geldigheid verloor. Wie dit op 'n gelyke vlak van bepaling en geldigheid wil plaas met die Christendom, bedryf ideologia en soms selfs meer: eidololatria.

Die Logos predik, leef en is geregtigheid. Elke ideologie wat die geskiedenis tot sover opgelewer het, is, predik en leef solank as hy duur, eiegeregtigheid. Eiegeregtigheid is nie die direk teenoorgestelde van geregtigheid nie, dis darem nie ongeregtigheid nie; inteendeel dit is 'n soort van geregtigheid, een wat van koers verander het en in sy eie baan gegaan het soos 'n sateliet wat amok maak. Dit het Jesus geweet. Die Bergrede plaas daarom nie eenkeer geregtigheid teenoor ongeregtigheid nie, maar konsekwent die geregtigheid teenoor die eiegeregtigheid.

Die Woord red sy gelowiges van die dood (Joh. 8:51; 5:24; $11: 25$ ). Die geskiedenis self is getuie dat die ideologie sy gelowiges en sy teenstanders gelykelik aan die dood oorlewer.

Omdat die ideologie van 'n à priori uitgaan, sigself tot 'n finale en afdoende gesag verhef, sluit dit onontkombaar die Woord as hoogste gesag af. Dit gebruik nog wel die Woord maar dan met allegoriese uitleg om die eie program en die eiesoortigheid te dien. Daarmee trek tot dusver elke ideologie 'n kombers oor die hemel en plaas 'n plafon tussen die hoorder van die Woord en God wat die Woord spreek. Daarom nog hierdie verskil tussen Woord en skynwoord: Omdat die Woord liefde en genade en waarheid is, openbaar dit God; die ideologie verberg God.

Hierdie stelling is nie vergesog nie. In die praktyk van die afgelope dertig jare het elkeen van die ideologieë die Christus van die Woord nog gereeld verban. Die Christus van die Woord kon, omdat Hy Jood was, onder die rasse-ideologie van die Naziisme in sy eie Kerk en in die fakulteite van Christelike Teologie nie inkom nie. Die Woord daarenteen nooi Christus altyd in: Kyk, Ek staan by die deur en Ek klop. As iemand my stem hoor en die deur oopmaak, sal Ek ingaan na hom toe en saam met hom maaltyd hou en hy met My".

A. S. Geyser. 